\title{
ON RUSSELL'S PUZZLE "THE PRESENT KING OF FRANCE IS NOT BALD"
}

\author{
ALEJANDRO MATUS
}

\begin{abstract}
Russell poses as a puzzle to solve the truth or falsehood of the expression "The present King of France is not bald" in relation to the law of excluded middle. He offers his proposal for a solution with a theory of denotation, characterized by an excessive complication, as he himself asserts. We argue that there is a simpler natural logical way out, based on the strict analysis of the contradictories and opposites of a proposition, and its exclusive disjunctions.
\end{abstract}

According to Bertrand Russell, theories like Frege's about denotation are wrong, and hence he seeks to develop an alternative proposal, which allows to solve a set of puzzles, among which he proposes the following:

"By the law of excluded middle, either 'A is B' or 'A is not B' must be true. Hence either 'the present King of France is bald' or 'the present King of France is not bald' must be true. Yet if we enumerated the things that are bald, and then the things that are not bald, we should not find the present King of France in either list" [3, p. 485].

However, after exposing his theory, he himself acknowledges:

"Of the many other consequences of the view I have been advocating, I will say nothing. I will only beg the reader not to make up his mind against the view -as he might be tempted to do, on account of its apparently excessive complication- until he has attempted to construct a theory of his own on the subject of denotation. This attempt, I believe, will convince him that, whatever the true theory may be, it cannot have such a simplicity as one might have expected beforehand" [3, p. 493].

Without making such an attempt in this paper, nor therefore talking globally about Russell's or Frege's theory of denotation, we consider that at least as far as the puzzle of "The present King of France" is concerned, a less complicated and more logically natural analysis than Russell's can be carried out, highlighting the characteristics of the logical denial and the disjunction in the case of the law of excluded middle.

Russell argues that the statement "The present King of France is bald" has meaning and "is certainly false" [3, p. 490]. Argument with which we agree. There are, on the other side, positions such as that of Strawson [5], who denies that such a statement may be significant, and therefore considers that it is neither true nor false. But we accept as convincing Russell's response to this, refuting Strawson

Key words and phrases. EXCLUDED MIDDLE CONTRADICTORIES AND OPPOSITES CONFUSION_AMBIGUITY_LOGICAL FALLACIES_REFERENCE_TRUTH. 
[4]. Discussion in which we do not go into detail in this paper. Here we focus on figuring out what happens after accepting that the statement is significant, and false when contrasted, as Russell does (or even by suppose its falsity as a mere initial hypotheses). Thus, from such a starting point, the contradictory statement "The present King of France is not bald" would have to be true, by the principle of exclusion of third. But, by other argument, "The current King of France is not bald" can be both true and false, Russell says.

It "is false if it means 'There is an entity which is now King of France and is not bald', but is true if it means 'It is false that there is an entity which is now King of France and is bald' ".

If false, the expression "The King of France" has a "primary figuration". If true, it has a "secondary figuration" [ 3, p. 490].

Let us ponder:

1. We argue that once it is accepted that "The present King of France is bald" is false, the statement "The present King of France is not bald" can only be logically true, because it is contradictory to a false proposition; and it is not sometimes true or sometimes false depending on the case. The latter is only applicable to the possible opposites that can, as something additional, specify the contradictory. The puzzle can be solved by a natural logic application of denial and disjunction. And you don't need for this a theory of denotation, although it may be required for other aspects.

We start from the basics: By the plain denial, we are talking about the contradictory one: $\neg \mathrm{A}$ is contradictory to $\mathrm{A}$, being its strict denial. As it is known, by the principle of excluded middle, $\neg \mathrm{A}$ is always only one. There cannot be two strict denials of A different from each other. Furthermore, as Aristotle points out,

"Things are said to be opposed to one another in four ways: as relatives or as contraries or as privation and possession or as affirmation and negation" [1, Categories 10 11b17].

In that sense, involving all those cases, we call n-opposites the number of opposites that correspond to a sentence. If the only opposed $\mathrm{B}$ of $\mathrm{A}$ is exactly the same contradictory $\neg \mathrm{A}$, then to $\mathrm{B}$ corresponds the 1-opposite; and there are no intermediate options: $\mathrm{B} \equiv \neg \mathrm{A}$. For example, in $\mathrm{A}=$ "x is an even natural number", the contradictory $\neg \mathrm{A}$ is "x is not an even natural number"; and $\mathrm{B}$ is the one and only one opposite. In $\mathrm{A}=$ "The color of $\mathrm{x}$ is white ", the contradictory $\neg \mathrm{A}$ is, exclusively, "The color of $\mathrm{x}$ is not white". And to B corresponds a large number of n-opposites, for example "black", "blue", "red", "green", etc. Of which only one can be true if A is false, for example, "The color of $\mathrm{x}$ is black" (again, by the principle of excluded middle, which here would discard any non-black color).

2. As is well known, the principle of excluded middle applies to strict denial, to contradictory propositions to each other, and not to n-opposite ones that go beyond mere denial; to "Either the color is white or the color is not white"; but not to "Either the color is white or the color is black". For black and white can be false at the same time.

Now, logically speaking, does exist the other option mentioned by Russell? Does "The present King of France is not bald" is true or false according to primary or secondary figuration? A logical fallacy that can appears is the confusion between strict contradictories and the opposites of an expression (contradictory + something: for example, "x is not white" + "is blue"). The opposite, in addition to mere denial 
affirms something else, except in the special case when it strictly coincides with the contradictory one. Accordingly,

(1) "The present King of France is bald",

which is false, has as contradictory, as mere denial, and not as an opposite,

(2) "The present King of France is not bald",

which must be therefore true, by the principle of middle excluded.

From "The present King of France is not bald" two possible opposites can be obtained. But those two opposites are two different expressions regarding the contradictory one. None of these opposites means exactly the same thing as that proposition, which is only a negation of (1). Those opposites can be exposed as Russell rethinks them (nevertheless he does not discern them as opposites, but as two forms that express plainly the same contradictory, depending on the case):

Either

(3) "It is false that there is an entity which is now King of France and is bald", which is true.

Or

(4) "There is an entity which is now King of France and is not bald", which is false.

For all this, the law of middle excluded cannot be applied to sentence (1) as contradictory to the opposites (3) or (4), but only respect to sentence (2), its strict denial. The problem comes down to consider false both, (1) and its opposite (4) (as in " $\mathrm{x}$ is white" against " $\mathrm{x}$ is black" to consider false both when for example $\mathrm{x}$ is red).

3. "The present King of France is not bald", as a contradictory expression of "The present King of France is bald", is not specific, not univocal (like all contradictory expressions, except those where there is only one opposite), because it implies two possibilities as opposites: (3) or (4). As also is not univocal, for example, "The color is not white" which implies many opposing possibilities.

It should be highlighted, then, that any denial, as long as it is a contradictory statement that additionally involves more than one possible n-opposition, is ambiguous; but ambiguous (sense-1) only in such a way that it is not univocal; but not in the sense-2 of not having a well-determined meaning ("The color is not blue" has an undeniable meaning, not ambiguous in sense-2, but it does not univocally specify (sense-1) the true color that is the case). In fact, expression (2) is ambiguous (not specific) with respect to (3) and (4) (the opposites), but not with respect to (1), being the clear and only denial of this last. In numerical base 3 there are only the ciphers 0,1 and 2. For any number's digit, either A) the digit is 0 , or $\mathrm{B})$ the digit is not 0 . If $\mathrm{B}$, then there are two new empirical options: either the cipher is 1 or it is 2 . B is not ambiguous in the sense-2 of equivocal, misleading or unclear. It is clear and univocal with respect to A. It is ambiguous in the sense- 1 of non-specific with regard to opposites. We don't need to specify the opposites of B to make a well-defined meaning. The law of the middle excluded is preserved just by take account of $\mathrm{B}$, without specifying the opposites that are the case. Without the need of identifying, for example, primary or secondary figurations. As in "The number is 8 or the number is not 8 " there is no ambiguity of meaning and the law is preserved; without specifying an opposite ("The number is 6 " or "The number is $9^{\prime \prime}$, etc.). 
4. In addition, it should be emphasized that the contradiction entails, where it corresponds to more than one possible n-opposite, a series of exclusive disjunctions (XOR in Boolean terminology) between each opposite. And it is sufficient the true of one of them so that the contradictory that implies such disjunctions is also true. Example: In "The color is white" the contradictory "The color is not white" implies the opposites of white in the color's universe: black XOR blue XOR red XOR green, etc. It is sufficient, for example, the true of the "black" opposite, for the disjunction to be true, and therefore it confirms that the contradictory one is true.

This also applies to the case of baldness dealt with by Russell. Which is not a special instance essentially different from the other cases whose examples we have put in this article. Thus, the contradictory $\neg \mathrm{A}=$ "The present King of France is not bald" gives rise to the mentioned two additional opposite possibilities, other than the contradictory one, diverse to the mere denial: (3) (that is true) XOR (4) (which is false).

And so the disjunction is true. That is, it confirms that the contradictory from which the statements in disjunction derive is true.

Russell says "The present King of France is not bald" can be both false and true, according to primary and secondary figurations. But from what we have already seen, it can actually only be true, by the principle of the middle excluded; and this true can be confirmed because one of the possible opposites in disjunction, derived from such expression, being true, also gives to that statement a value of truth. The ones he calls primary and secondary figurations are only, actually, the specific dichotomies, 2-opposites (contradictory + something), of the statement $\mathrm{A}=$ "The present King of France is bald" encompassed as exclusive disjunctions implied by the contradictory $\neg \mathrm{A}=$ "The present King of France is not bald". Hence, $\neg \mathrm{A} \neq$ (3) and $\neg \mathrm{A} \neq(4)$. Viz. $\neg \mathrm{A}$ doesn't means (3) nor (4). That is, (3) and (4) do not perform their figuration in the contradictory (2), as Russell believes, but in the opposites.

Primary or secondary figurations occurs only if we want to call primary figurations the opposites that make the sentence false, and secondary figuration the opposite that makes the sentence true. But it is up to us not to confuse the contradictory with the opposites. In this sense, primary or secondary figurations can be only empirical: they do not depend on their truth more than on the facts (for example whether the color is black XOR not, and if there are a certain number of options into non-black. Or, with only two options, whether there is an entity which is now King of France and is not bald XOR there is not an entity which is now King of France and is not bald) and not on a formal logical question. Which is clearer when there are more than two possible opposed options. In this case, all possible options that do not occur may be called "secondary figurations", after empirically determining which one is the opposite that occurs in the facts, which may be called the "primary figuration".

Once we establish by experience, or even assume as a premise, that "The present King of France is bald" is false, the truth or falsehood of his plain denial no longer depends on a theory of denotation or reference, and we don't need, at that point, to

"enumerate the things that are bald, and then the things that are not bald" to find, or "not find the present King of France in either list" [3, p. 485]. 
Logical analysis based rigorously on excluded middle is necessary and sufficient. When to the contradictory corresponds more than one additional exclusive disjunction, is enough the empirical selection of the opposite option that the case may be; enumerating, only until that moment, those things that are bald, and then the things that are not bald (cf. what Kant names polytomy:

"A division into two members is called dichotomy; but if it has more than two members, it is called polytomy. ... Polytomy cannot be taught in logic, for it involves cognition of the object. Dichotomy requires only the principle of contradiction, however, without being acquainted, as to content, with the concept one wants to divide" ([2], section 113).

In short, in order to save the validity of the principle of third excluded in the puzzle raised by Russell, it is not necessary to rethink the contradictory as a logical expression without grammatical subject, nor to appeal to different figurations in the same contradictory judgment; it is sufficient to adequately distinguish the contradictory from the opposites.

\section{REFERENCES}

[1] Aristotle. Categories and De lnterpretatione. Oxford University Press Inc., New York, 2002.

[2] Kant, Immanuel. Logic Jäsche, 1800. Lectures on Logic, J. M. Young ed., Cambridge University Press, Cambridge, 1992.

[3] Russell Bertrand. On denoting. Mind, New Series, Vol. 14, No. 56, Oct. 1905, pp. 479-493. Oxford University Press. https://doi.org/10.1093/mind/XIV.4.479

[4] Russell Bertrand. Mr. Strawson on referring. Mind, Volume LXVI, Issue 263, July 1957, pp. 385-389. Oxford University Press. https://doi.org/10.1093/mind/LXVI.263.385

[5] Strawson P. F. On Referring. Mind, New Series, Vol. 59, No. 235, Jul. 1950, pp. 320-344. Oxford University Press, https://doi.org/10.1093/mind/LIX.235.320

[6] Whitehead Alfred North, Russell Bertrand. Incomplete symbols: Descriptions. 1910. Jean van Heijenoort ed. From Frege to Gödel. A source book in mathematical logic, 1879-1931. pp. 216-223. Harvard University Press, Cambridge, Massachusetts, 1967.

ALEJANDRO MATUS. CUPA-H, CD. DE MÉXICO. C.P. 03100. MÉXICO. alejandromatusunfe020@gmail.com 